\title{
THE APPLICATION OF LASER DIFFRACTION ANALYSIS FOR GRAIN SIZE DETERMINATION OF CURRENT DEPOSITS OF VJOSA RIVER DELTA LITTORAL (ALBANIA)
}

\author{
Emiriana Xhaferri ${ }^{*}$

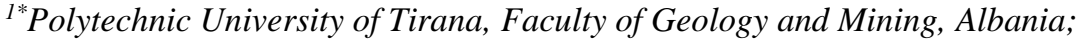 \\ "Corresponding Author Emiriana Xhaferri, e-mail: emirianaxh@ hotmail.com;
}

Received December 2019; Accepted January 2020; Published March 2020;

DOI: https://doi.org/10.31407/ijees10.211

\begin{abstract}
Vjosa River sources from Pindus Mountains in Greece, with a length of $272 \mathrm{~km}$ and drains in the southern of Albania. The surface of Vjosa river drainage basin is $6700 \mathrm{~km}^{2}$. The surface of the river delta is $317 \mathrm{~km}^{2}$, and stretches from Hoxhara channel in the north to the Zvërnec molasses hills in the south. The study area is characterized by sandy banks, mud flats, salt marshes, small lagoons, and temporary marshes. This delta presents a coastal area up to $12.6 \mathrm{~km}$ toward the south and $9.5 \mathrm{~km}$ in the north. For the analysis of the grain size distribution and sediment parameters such as mean, standard deviation or sorting, skewness and kurtosis of Vjosa river delta a Laser diffraction Analysis was applied. The measurements were performed using a Malvern instrument while the data processing was carried out by Mastersizer 2000 software. The bivariate analysis, linear discriminant functions (LDF), passega diagrams (CM plots) were used for 50 samples, in order to study the depositional processes, hydrodynamic conditions, mechanism of sedimentation and depositional environments. The results show that samples of the Vjosa river delta consist of fine to medium sand, well sorted, near symmetrical, mesokurtic to very leptokurtic. The linear discriminant functions analysis indicates that sediments were reworked by Aeolian and Beach processes under the environment of shallow marine and fluvial deposits. Results of passage diagrams (CM plot) reveal that sediments were deposited by bottom suspension and rolling-PQ and less graded suspension-QR, as well as rivers and by tractive currents.
\end{abstract}

Keywords: Bivariate plots, Grain size distribution, Linear discriminant functions, Passega diagrams, Vjosa River Delta 